Bender, A. E. (1954). Private communication.

Block, R. J. \& Mitchell, H. H. (1946-7). Nutr. Abstr. Rev. 16, 249.

Fernell, W. R. \& Rosen, G. D. (1956). Brit. F. Nutr. 1o, 143.

Kidder, G. W. \& Dewey, V. C. (195I). In Biochemistry and Physiology of Protozoa. Vol. I, p. 323.

[A. Lwoff, editor.] New York: Academic Press Inc.

Miller, D. S. \& Bender, A. E. (1955). Brit. F. Nutr. 9, 382.

\title{
The effect of complete hepatectomy on the utilization by rats and rabbits of intravenously administered aqueous dispersions of carotene
}

\author{
By N. A. WORKER \\ Biochemistry Department, Massey Agricultural College (University of New Zealand), \\ Palmerston North, New Zealand \\ (Received 24 Fanuary 1956)
}

It is now well established that carotene, administered intravenously as an aqueous dispersion, can be converted into vitamin A by rats and rabbits (Bieri \& Pollard, 1954; Bieri, 1955; Kon, McGillivray \& Thompson, 1955; McGillivray, Thompson \& Worker, I956). The site of conversion has, however, not as yet been determined. It was originally suggested by Mattson, Mehl \& Deuel (1947) that parenterally administered carotene might be utilized after being secreted into the intestine by way of the bile. Bieri \& Pollard (1954), however, could find no decrease in conversion by rats in which the bile duct had been completely ligated, or in rats from which the small intestine had been removed, and concluded that rats can effectively convert injected carotene at a site other than the small intestine. In further experiments the same authors showed that nephrectomized rats, and rats in which up to $75 \%$ of the liver tissue had been removed, formed about as much vitamin A after intravenous injection of carotene dispersions as intact controls. Though it appeared probable from these experiments that the utilization of carotene was independent of the liver, there was still the possibility that sufficient functional liver tissue remained to effect conversion. For this reason it was thought desirable to repeat the experiments in the complete absence of the liver. The results of preliminary experiments involving complete hepatectomy in rats have already been reported (McGillivray et al. 1956). The present paper covers subsequent work in this laboratory with hepatectomized and hepatectomized-eviscerated rats and with hepatectomized rabbits.

\section{EXPERIMENTAL}

General. The methods and materials were essentially the same as those described by McGillivray et al. (1956).

Rats. The rats used in these experiments were inbred albino animals of the Wistar strain from the Massey College small-animal colony, maintained on the basal diet of 
pellets similar to that of McGillivray et al. (1956). Unless otherwise stated all animals were partially deficient in vitamin $A$, as evidenced by low levels of vitamin $A$ in the blood and the absence of detectable quantities of vitamin $\mathrm{A}$ in the liver.

Rabbits. The rabbits used were from an inbred strain of smooth-coated albinos supplied by the Ruakura Animal Research Station small-animal colony. They were maintained on a basal diet similar to that of the rats and received in addition a generous allowance of fresh grass daily. Their vitamin A blood levels and liver stores would, therefore, be expected to lie within the normal range.

Surgical procedure in the rabbit. Diethyl-ether anaesthesia was used throughout all operations. The technique of liver removal was, in the main, similar to that described previously for the rat by McGillivray et al. (1956). After subcutaneous injection under the foreleg of $3 \mathrm{ml}$. saturated glucose solution, the animals were opened by ventral mid-line and left lateral incision. The aorta was ligated directly above the junction of the coeliac artery, the vena porta as closely as possible to the liver and the vena cava immediately below the liver. Next, the liver was tied off below the diaphragm, and the whole organ removed. A ro $\mathrm{ml}$. control blood sample was then taken from the lower vena cava. Carotene in Tween 40 (polyoxyethylenesorbitan monopalmitate, Atlas Powder Co., Wilmington, Delaware), was immediately injected directly into the jugular vein, and the animals were allowed to recover from the anaesthetic; they were again anaesthetized $\mathrm{I}-2 \mathrm{~h}$ later and bled by cardiac puncture. From animals of sufficient size an additional $10 \mathrm{ml}$. blood sample was also taken from the jugular vein after half an hour.

Evisceration in the rat. The rats used for this experiment were stock-colony breeding does with high liver stores. After removal of the liver, the viscera, comprising the stomach, small intestine, large intestine, kidneys, pancreas, adrenals and gonads, were completely removed from four rats. The cavity was then lightly swabbed with $\mathbf{I}$ in 30,000 adrenaline solution before injection of carotene in Tween into the jugular vein. The hepatectomized-eviscerated animals were re-anaesthetized after $\frac{1}{4} \mathrm{~h}$, and blood samples were taken in the normal way by cardiac puncture.

Sampling and assay of blood. After removal of the liver by the method described above, the blood circulation of the animal was virtually restricted, apart from a small amount of collateral circulation through the body wall, to the anterior part of the body. In the rat this situation made it difficult to obtain sufficient blood from individual animals for assay purposes. For this reason blood was usually bulked from two or three rats, so as to yield not less than $3 \mathrm{ml}$. plasma. In order to gain some idea of the extent of collateral circulation to the posterior part of the body after liver removal, blood samples were also taken from the vena cava of the hepatectomized rats at slaughter and similarly bulked for assay. This procedure was not applied to rabbits, however, because, as noted earlier, after removal of the liver and immediately before injection all blood in the vena cava was withdrawn to provide the predosing (control) sample. Blood was assayed for carotene and vitamin A alcohol only, since, as has been previously noted by Kon et al. (1955), variations in blood vitamin A ester after intravenous injection of carotene in Tween are slight. 
RESULTS

Conversion in hepatectomized rats. Table I (Exp. I) clearly shows that hepatectomized rats formed vitamin A from intravenously injected aqueous dispersions of carotene as efficiently as intact rats in these experiments or in those of McGillivray et al. (1956).

It is interesting to note that carotene was present in blood from the posterior vena cava of hepatectomized rats at slaughter in concentrations ranging from 15 to $25 \%$ of that in the anterior blood obtained by heart puncture (Table I). Although this finding confirms the presence of collateral circulation through the body wall to the lower part of the body, the extent of the circulation and its bearing on the present studies would seem to be limited.

Conversion in hepatectomized-eviscerated rats. Table I (Exp. 2) clearly shows that hepatectomized-eviscerated rats are capable of converting intravenously injected aqueous dispersions of carotene into vitamin A. Thus, within $\frac{1}{4} \mathrm{~h}$ of injection of $320 \mu \mathrm{g}$ carotene, values for plasma vitamin A alcohol increased from to to $40 \mu \mathrm{g} / \mathrm{100} \mathrm{ml}$. plasma, i.e. to a value similar to that recorded for hepatectomized and intact animals.

Conversion in hepatectomized rabbits. In rabbits the general picture was essentially the same as in rats, although the rabbits converted carotene less efficiently (Table 2), an observation confirming that made previously by Kon et al. (I955) on intact animals. However, as the injection of Tween or distilled water alone caused a decrease in plasma vitamin A of $19 \mu \mathrm{g}$ (range ${ }_{13}-27$ ), the increase of $9 \mu \mathrm{g}$ (range $5^{-12}$ ) corresponds to a total change of $28 \mu \mathrm{g}$, or a $50 \%$ increase, leaving little doubt that in the rabbit, as in the rat, the liver is not required for the conversion of intravenously injected carotene.

\section{DISCUSSION}

The main purpose of the present experiments was to establish whether animals normally capable of converting intravenously administered aqueous dispersions of carotene into vitamin A can do so in the complete absence of the liver. For this purpose rats and rabbits were used, since it has been well established that these species effectively convert injected carotene, provided it is dispersed with a suitable surfaceactive agent such as Tween 40 . In rats the results provide clear evidence, based on the increase of plasma vitamin A alcohol after injection, that the hepatectomized animal converts carotene in Tween into vitamin $A$ at a normal rate. Further, in hepatectomized-eviscerated animals formation of vitamin A from carotene proceeded at an undiminished rate.

In hepatectomized rabbits the increases in plasma levels of vitamin A alcohol after injection of carotene were considerably smaller than in rats, owing possibly to the lower dose of carotene administered on a weight basis or to a species difference in the efficiency or rate of conversion (Kon et al. 1955). Since, however, in undosed animals, and in animals dosed with distilled water or Tween alone, plasma alcohol levels decreased steadily after hepatectomy, and since carotene administration offset and reversed this trend, there would appear to be no doubt that the formation of vitamin $\mathrm{A}$ after injection of carotene dispersions into hepatectomized rabbits is independent of the presence of the liver. 


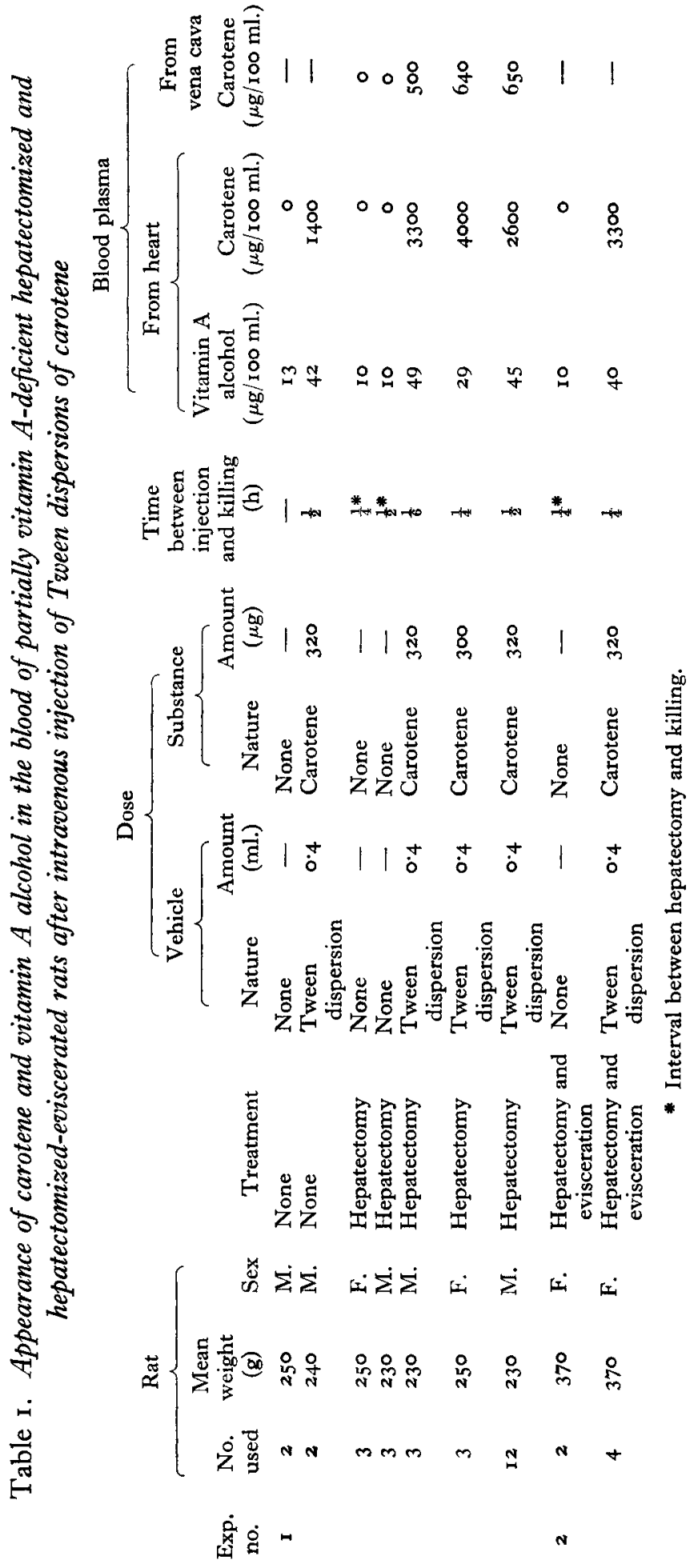


Vol. 10

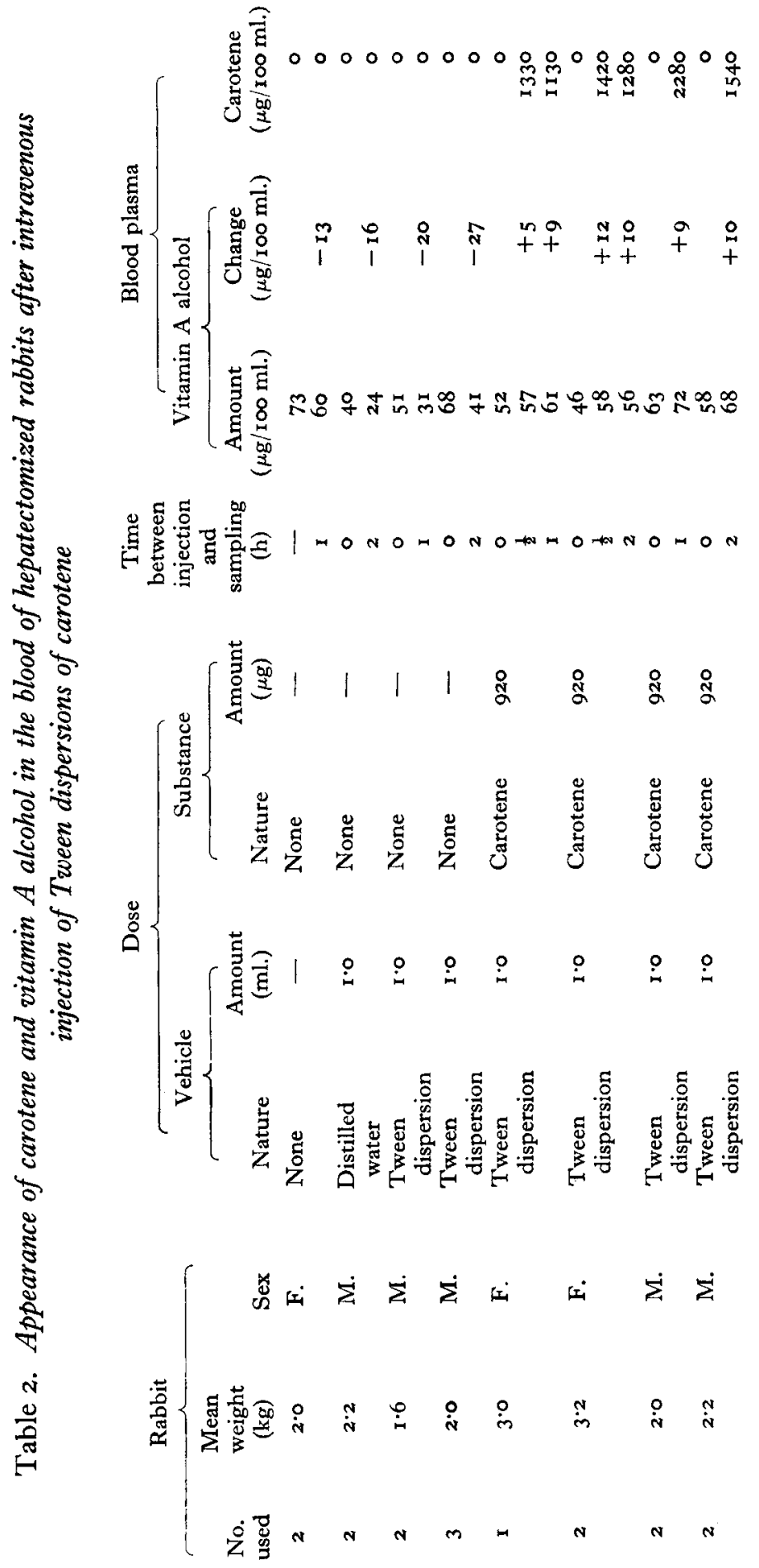


The reason for the sharp drop in vitamin $A$ in the blood of hepatectomized rabbits not dosed with carotene is at present a matter for conjecture. It is problematic whether this drop is due to the shock of operation, as Kon et al. (r955) found marked fluctuations in the blood of rabbits after simple venepuncture and a frank decrease after the venepuncture of rabbits injected with Tween.

It is of interest to note in passing that in these experiments vitamin A was formed after injection of Tween dispersions of carotene in the absence not only of the liver but of many other organs and tissues. For example, as previously reported by Bieri \& Pollard (1954), the appearance of vitamin A was unaffected by the removal of the bile duct, the small intestine or the kidneys. Similarly, the level of vitamin A circulating after injection was not diminished by removal of the stomach, large intestine, pancreas, adrenals or gonads or by complete ligation of all the major blood vessels supplying the lower half of the body.

These results support the opinion of Bieri \& Pollard (1954), with which Kon et al. ( 1955 ) concur, 'that perhaps many tissues possess the ability to convert carotene'. The further possibility must, however, be considered, that other tissues in the anterior half of the body are specifically involved in conversion. The evidence presented by McGillivray et al. (I956) gives good grounds for rejecting the thyroid as the site of conversion. It has been suggested, however, by Kon et al. (1955) that the lungs may play an important part in the metabolism of intravenously administered dispersions of carotene. Experiments are, therefore, at present being planned in this laboratory to test this possibility, and it is hoped to present them in a later communication.

\section{SUMMARY}

I. 'The utilization of intravenously injected Tween dispersions of carotene has been studied in hepatectomized and hepatectomized-eviscerated rats and in hepatectomized rabbits.

2. After injection of $300-320 \mu \mathrm{g}$ carotene into hepatectomized rats, plasma vitamin $\mathrm{A}$ alcohol increased markedly from to to as much as $49 \mu \mathrm{g} / \mathrm{r} 00 \mathrm{ml}$. plasma at various intervals of up to $\frac{1}{2} \mathrm{~h}$ after injection.

3. In hepatectomized-eviscerated rats injection of $320 \mu \mathrm{g}$ carotene in Tween caused an increase in vitamin $\mathrm{A}$ alcohol of the plasma from 10 to $40 \mu \mathrm{g} / \mathrm{100 \textrm {ml }}$. plasma within $\frac{1}{4} \mathrm{~h}$.

4. Injection of $920 \mu \mathrm{g}$ carotene into hepatectomized rabbits caused an increase in vitamin $\mathrm{A}$ alcohol in the blood of up to $10 \mu \mathrm{g} / \mathrm{I} 00 \mathrm{ml}$. plasma within $2 \mathrm{~h}$. In the absence of injected carotene, however, alcohol levels decreased in a spectacular fashion after hepatectomy, a maximum drop of $27 \mu \mathrm{g} / 100 \mathrm{ml}$. plasma being recorded after $2 \mathrm{~h}$.

5. From these results it is concluded that the conversion of intravenously injected dispersions of carotene in Tween is not adversely affected by complete removal of the liver in rabbits or by complete removal of the liver alone or of both liver and viscera in rats.

The results of this investigation form a section of a thesis submitted in partial fulfilment of the requirements for the degree of Ph.D. of the University of New 
Zealand. The author wishes to express thanks to Dr W. A. McGillivray of the Biochemistry Department, Massey College, for his help and co-operation throughout, and to the Department of Scientific and Industrial Research for a grant towards the investigation. The technical assistance of Miss Fay Frecklington is gratefully acknowledged.

\section{REFERENCES}

Bieri, J. G. (1955). Arch. Biochem. Biophys. 56, 90.

Bieri, J. G. \& Pollard, C. J. (1954). Brit. F. Nutr. 8, 32.

Kon, S. K., McGillivray, W. A. \& Thompson, S. Y. (1955). Brit. F. Nutr. 9, 244.

McGillivray, W. A., Thompson, S. Y. \& Worker, N. A. (1956). Brit. F. Nutr. ro, 1 26.

Mattson, F. H., Mehl, J. W. \& Deuel, H. J. Jr. (1947). Arch. Biochem. 15, 65. 